\title{
AS HISTÓRIAS DE VIDA COMO TRAMAS DE FIOS NA COMPOSIÇÃO DA PROFESSORALIDADE ${ }^{1}$
}

JUSSARA MIDLEJ

Universidade Estadual do Sudoeste da Bahia

\section{MARCOS VILLELA PEREIRA}

Pontificia Universidade Católica do Rio Grande do Sul

RESUMO Este texto trata de uma investigação-formação realizada numa abordagem (auto)biográfica, entre 2013 e 2014, numa turma de Pedagogia, integrada ao Plano Nacional de Formação de Professores da Educação Básica (PARFOR), em colaboração com a Universidade Estadual do Sudoeste da Bahia (UESB), no campus de Jequié. As escritas de si, concretizadas nos memoriais, e as ações realizadas nos ateliês deramse num plano extensional de recolha de informações, em diferentes circunstâncias e contextos, com a finalidade de expandir o campo dos possiveis, com retornos aos materiais produzidos no processo profissional e formativo. As conversações, como ações de reciprocidade, foram relacionadas à triangulação formativa e às histórias de vida, em contextos de pesquisa e formação. Os agrupamentos, com repetidas análises compreensivas das informações produzidas, demonstraram alargar as perspectivas docentes e ampliar as caracteristicas formativas dos atos de narrar-se e às práticas educacionais cotidianas. Nos partícipes, o acréscimo das percepções de si e o aguçamento de seus entendimentos acerca das situações e das experiências ficaram patentes; contribuíram para a concepção da formação como autoformação, demonstrando que o ser humano, ao viver experiências de si rearranja, atualiza-se, diferencia-se continuamente, produz forças vitais criadoras de estados inéditos de ser professor.

Palavras-chave: Ateliês (auto)biográficos. Histórias de vida. Narrativas de formação. Experiências.

\section{ABSTRACT LIFE STORIES AS PLOTLINES IN THE COMPOSITION OF PROFESSORALITY}

This text deals with a formation-research conducted through an (auto)biographical approach, between 2013 and 2014, in a pedagogy

1 Este trabalho se inscreve no âmbito de pesquisa financiada com Bolsa de Produtividade CNPq para Marcos Villela Pereira, que acolheu a supervisão de estágio pós-doutoral de Jussara Midlej. 
class, integrated into the National Plan of Basic Education Teachers Formation (NPBETF) in collaboration with the State University of Southwest Bahia (UESB) at the Jequié campus. The self-writings, concretized in the memorials, and the actions taken in the workshops, took place in an extensional plan to collect information in different circumstances and contexts, in order to expand the field of possibilities with returns to the materials produced in the professional and educational process. The dialogues, as reciprocal actions, were related to formation triangulation and life stories in research and formation contexts. The groupings, with repeated comprehensive analyses of the produced information, demonstrated a broadening of the teaching perspectives and an expansion of the formative characteristics of the acts of narrating oneself and the daily educational practices. For the participants, the increase in perceptions of themselves and the sharpening of their understandings about the situations and experiences were patent; They contributed to the conception of formation as self-formation, demonstrating that the human beings, by living self-experiences rearrange and update themselves, differing continuously and producing vital creative forces of the original states of being a teacher.

Keywords: (Auto)biographical workshops. Life stories. Formation narratives. Experiences.

\section{LAS HISTORIAS DE VIDA COMO TELARES DE COMPOSICIÓN DE LA PROFESORALIDAD}

Este texto resulta de una investigación/formación realizada en una aproximación (auto)biográfica, entre 2013 y 2014, a una clase de Pedagogía, integrado en el Plan Nacional de Formación de Profesores de Formación Básica (PARFOR), en colaboración con la Universidad del Estado de Suroeste de Bahía (UESB) en el campus Jequié. Los escritos propios, realizados en el memorial, y las medidas adoptadas en los estudios dieron un plan de extensión para la recogida de información en diferentes circunstancias y contextos, con el fin de ampliar el campo de posibilidades con retorno a los materiales producidos en el proceso de formación profesional. Las conversaciones y las acciones recíprocas estaban relacionados con la formación y las historias de vida en contextos de investigación y formación. Agrupaciones, con el análisis integral repetida de la información producida, demostraron ampliar las perspectivas de los maestros y ampliar las características de formación de los actos de narración y las prácticas educativas cotidianas. Los parti- 
cipantes, en el incremento en la percepción de sí mismos, tornaron más precisa su comprensión acerca de las situaciones y experiencias y contribuyeron al diseño de la formación y autoformación, lo que demuestra que el ser humano, al vivir experiencias de si se actualiza, se diferencia continuamente, produce fuerzas vitales creadoras de estados inéditos de ser profesor.

Palabras clave: Talleres (auto)biográficos. Historias de vida. Narrativas de formación. Experiencias.

\section{Introdução}

A denominada investigação-formação, com evidências (auto)biográficas, traz contribuições ao método biográfico para a formação de professores, sendo identificada, no campo da Educação, com as práticas culturais e sociais, discursivas, como produção de significados relacionados a circunstâncias históricas. Nas Ciências Humanas, advém do século XIX, na Alemanha, como opção à sociologia positivista. No decorrer de sua evolução, desencadeou importantes polêmicas epistemológicas e metodológicas, ampliando possibilidades de superação dos estudos relacionados a esta concepção. As designadas histórias de vida vêm sendo valorizadas por uma extensa tradição hermenêutica relacionada a autores como Dilthey (2010); Foucault (1993; 2001; 2004a; 2004b); Gadamer (1997); Ricoeur (1990; 1995; 2007) e, em dimensões fenomenológicas, a Berger e Luckmann (2003) e Schütz (1979; 1987). Ao ganhar ênfase internacional, buscou as relações entre existir e narrar, implicada em atos mediacionais voltados à reflexividade autobiográfica e à consciência histórica - em especial conectadas à educação de adultos.

Um dos pioneiros desse movimento, também da vertente europeia, Gaston Pineau, publicou, em 1980, uma obra que marcou “[...] o início da utilização sistemática do método biográfico no âmbito da Educação Permanente e da Formação de Adultos" (PINEAU, 2004, p. 25), na qual analisa as histórias de vida como um método de investigação-ação relacionado à autoformação; além dele, o pesquisador Pierre Dominicé (2010) utilizou o conceito de biografia educativa, como instrumento de investigação para a educação de adultos, aproximando o biográfico do educativo. A corroborar com seus colegas, Ferrarotti (2010, p. 39) argumenta que "[...] os materiais utilizados pelo método biográfico são, na maioria, autobiográficos". Ao ganhar tal relevância, a pesquisa biográfica associou-se à formação de professores, em especial a partir das contribuições aos quadros epistemológicos e metodológicos de outros estudiosos europeus da biografização, como Delory-Momberger (2006; 2008), Nóvoa e Finger (2010), Dominicé (2010), Pineau (2004), Josso (2010) e Ferrarotti (2010).

No Brasil, as pesquisas de cunho (auto)biográfico, relacionadas à formação de professores, passaram a ter relevância, precisamente, a partir de 1980, quando o estudo da subjetividade foi salientado como o eixo agregador de toda a discussão, seguindo o movimento socioeducativo da formação docente, na perspectiva de uma “[...] reflexão sobre os princípios epistemológicos, metodológicos, éticos e deontológicos ${ }^{2}$ nas histórias de vida como pro-

2 O código deontológico, quer seja formal ou informal, é de ordem ideológica e moral, elementos que dão coesão a um grupo profissional, pois visa defender o estatuto e o prestígio social de seus membros sem pôr de lado a defesa dos interesses socioeconômicos e profissionais destes. (SOUSA, 2000). 
cedimento de pesquisa, formação e intervenção" (PASSEGGI, 2010, p. 30). Tais princípios, desde o início do século $X X$, vêm se revelando “[...] não apenas como um instrumento de investigação, também (e, sobretudo) como um instrumento de formação" (PASSEGGI, 2010, p. 23). Nesse sentido, numa importante conquista, a LDBEN determinou a “[...] exigência de curso de nível superior de graduação plena em universidades e Institutos Superiores de Educação, para substituir o curso de magistério do nível médio" (ARANHA, 2006, p. 326). A formação docente, agora não mais vinculada apenas ao aspecto de dar forma a, passou a envolver, também, estratégias de estranhamento de políticas de cognição cristalizadas, como modos de construir outros modos de relação com o mundo, consigo mesmo, com pessoas, com a profissão. Vêm assim se constituindo em marcos de referências e elementos desencadeadores de dispositivos processuais indispensáveis aos percursos de formação docente; já há, nestas, reconhecidamente, uma potencialidade como elemento formativo e como método qualitativo de investigação e, com isso, uma compreensão da docência como composição de forças que entrelaça vida e profissão, “[...] numa pregnância subjetiva" (FERRAROTI, 2010, p. 43) a apontar a incoerência de se separar as dimensões pessoais das profissionais e viceversa. Nóvoa (1995, p. 8) afiança, nesse sentido, que "[...] as abordagens (auto)biográficas podem ajudar a compreender melhor as encruzilhadas em que se encontram actualmente os professores [...] e delinear novas práticas de acção, investigação e formação".

Em setembro de 2004, aconteceu na Pontificia Universidade Católica do Rio Grande do Sul (PUCRS), em Porto Alegre, um relevante debate internacional - o I Congresso Internacional sobre Pesquisa (Auto)biográfica (CIPA). Pela primeira vez, no nosso país, reuniram-se grupos de pesquisadores, nacionais e estrangeiros, sobre o método biográfico como metodologia autônoma, no domínio das ciências da educação, o que abriu possibilidades de discussão sobre as escritas de si, memórias, histórias de vida, práticas de formação, trazendo uma contribuição significativa para a área denominada, no Brasil, de pesquisa (auto)biográfica. Esta nomenclatura, com a primeira expressão entre parênteses veio do grupo de Portugal, como forma de abarcar, num complexo, as dimensões pessoais, “[...] a narrativa do outro como um dos lugares onde experimentamos nossa própria construção biográfica" (DELORYMOMBERGER, 2008, p. 22). Nessa mesma direção, Souza (2004, p. 148), reitera que “[...] a utilização dos parênteses, por Nóvoa (2010), traz a simplificação do duplo sentido da expressão, como movimento de investigação e de formação, evidenciando a narrativa do ator social", a refletir sobre o cunho formativo contido nesse processo, o envolvimento do sujeito, ao narrar suas histórias, e à implicação do pesquisador nos contatos consigo mesmo e com o outro.

\section{O movimento constitutivo desta investigação-formação e seus acontecimentos}

Numa abordagem (auto)biográfica, a partir do enfoque qualitativo, a presente investigação/ formação processou-se entre 2013 e 2014 alinhada a um estágio pós-doutoral, realizado na PUCRS, conectando-se a uma ação metodológica qualitativa na probabilidade de reconstrução da experiência e na direção de produzir composições, a partir de tramas (in)visíveis de forças humanas interagentes. A ação deu-se numa turma de Pedagogia, agregada ao Plano Nacional de Formação de Professores da Educação Básica (PARFOR), em cooperação com a Universidade Estadual do Sudoeste da Bahia (UESB), no interior do campus acadêmico de Jequié. A denominada Plataforma Freire (PAR- 
FOR) processa-se em regime de colaboração entre a Coordenação de Aperfeiçoamento de Pessoal de Nivel Superior (CAPES), os Estados, os municípios, o Distrito Federal e as Instituições de Educação Superior (IES), e foi instituída no Brasil pelo Ministério da Educação (MEC), em atendimento ao disposto no artigo 11, inciso III do Decreto no 6.755, de 29 de janeiro de 2009 (BRASIL, 2009).

$\mathrm{Na}$ presente ação, negociamos com a coordenação do Curso de Pedagogia, no sentido de garantir um espaço de docência numa turma de professores dos anos iniciais, recém-chegada ao processo acadêmico; com isso, adentrei o grupo na condição de docente da área de Educação Infantil e, desde os primeiros momentos, aos professores/alunos, evidenciei a intencionalidade de realizar, concomitantemente ao andamento da disciplina, uma investigação/formação de acordo com os princípios da pesquisa (auto) biográfica, acoplada ao citado estágio pósdoutoral, que vinha sendo realizado na PUCRS. Explicitei, ainda que, no cerne da ação pretendida, havia um sentido de investigar linhas históricas de profissionais que retomaram aos estudos, após concluírem antigos cursos de Magistério e que, para tal, eu gostaria de contar com a classe ou até mesmo alguns voluntários, inclusive em momentos extraclasse. Com isso, na primeira oportunidade, apresentei aos professores/alunos a possibilidade de realização de atividades acadêmico-cientíico-culturais certificadas (MEC/CNE/CES Artigo 8o § III), de acordo com o parecer 05/2005 das Diretrizes Curriculares do Curso de Pedagogia e, a partir dali, alguns deles, voluntariamente, aderiram à realização de atividades no interior dos módulos de estudos acadêmicos. Estas atividades passaram a ocorrer como estratégia metodológica de pesquisa, na forma de "prática de estudos e atividades independentes, transversais, opcionais, de interdisciplinarida- de, especialmente nas relações com o mundo do trabalho".

A partir de tais combinações, ficou acordada a operacionalização de ateliês autobiográficos (DELORY-MOMBERGER, 2008), conversações e a elaboração de portfólios com 17 dos 34 professores/alunos, que se voluntariaram, na citada turma; o grupo foi composto por 15 mulheres e 2 homens, com idades entre 25 e 50 anos, e uma média de 15 anos de exercício docente, que participariam de atividades diferenciadas, específicas e complementares, relacionadas a este estudo. À época, estes professores se encontravam atuando, de modo polivalente, em redes públicas municipais de ensino da microrregião sudoeste da Bahia. Ao propor sua realização, mobilizou-me o desejo de um exercício estético-pedagógico relacionado a um potencial de transformação, de produção de estados diferentes de ser (DELEUZE, 1988), numa compreensão de que "a formação se articula numa abertura para novas construções de si" (HERMANN, 2008, p. 33). Epistemologicamente, houve uma suposição de que as histórias de vida, ao comporem um cenário problematizador de pesquisa, poderiam favorecer dispositivos processuais desequilibradores e, talvez, produtores de novas composições (DELEUZE, 1991), reconhecidamente indispensáveis às circunstâncias de formação docente. Assim, após os acordos iniciais, externei a expectativa de que esse processo contivesse "[...] uma característica universal da formação, o manter-se aberto para o diferente, para outros pontos de vista mais universais" (GADAMER, 1997, p. 360).

$\mathrm{Em}$ tais sintonias, foram realizados quatro ateliês (auto)biográficos, com a duração, média, de quatro horas cada um, denominados de ateliês de escrita (auto)biográfica, por Passeggi (2008). Estes ocorreram como estratégia metodológica central, a partir de adaptações dos procedimentos utilizados nos Ateliês Biográficos de Projeto (ABP), de Delory-Momber- 
ger (2006). Aconteceram a partir do princípio epistemológico de que os professores são produtores de conhecimento e se constituíram na perspectiva de reconstrução da experiência - como poiésis, como criação - em processos de composição de subjetividades, na direção de produzir o mundo da cotidianidade (JOUTARD, 2000), a partir de tramas (in)visiveis de ações humanas interagentes. As elaborações das narrativas de si e da profissão docente, ao serem encaminhadas na perspectiva da problematização, foram concretizadas nos intervalos, entre um ateliê e outro, em denominados memoriais que, como linhas de tempo se abrindo em ondas de subjetividade, rupturas, marcas e lacunas, marcavam a vida vivida, plena de virtualidades. Nesses sentidos, ocorreram perspectivados aos princípios metodológicos e éticos das histórias de vida, como procedimento de pesquisa, formação e intervenção (PASSEGGI, 2010), estando centrados no diálogo, sob o entendimento gadameriano de que, nele, a linguagem se forma, amplia e atua. Como eixos agregadores, os estudos de Pereira (2001; 2010a; 2010b) foram aportes valiosos ao esclarecimento de que "[...] a escolha de ser professor passa, necessariamente, pela reconstituição de alguns fatos que antecedem a essa decisão" (PEREIRA, 2001, p. 32). Nestes, o citado pesquisador (PEREIRA, 2001, p. 32), ao invés de simplesmente inquirir: "O que é ser professor?" - problematiza: "Como se é professor?" "Por que se é professor?" Ao se alinhar a tais inquietações, ele revela que não se encontra em busca da identidade do docente e, sim, de marcas e efeitos produzidos no (e pelo) sujeito-em-prática, em processos de devir (como potencial de vir a ser algo ainda não sido), numa realidade que ultrapassa o preestabelecido, o estável. De minha parte, ao sintonizar com tal viés epistemológico, houve um reconhecimento de que os movimentos de vida (e suas narrativas) se constituem em elementos desencadeadores de dispositivos processuais, em configurações de estados de ser singulares (DELEUZE; GUATTARI, 1995).

No decorrer desta ação, os focos foram as histórias de vida, especialmente pautadas na vida escolar e na ação profissional docente, em dimensões que favoreceram conexões de abertura entre o individual e o coletivo. Desse modo, as narrativas de vida dos partícipes foram trazendo à pauta processos de individuação (SIMONDON, 1989), que foram deixando transparecer não somente o indivíduo, mas o par indivíduo-meio, em atos, não apenas cognitivos, como se pode observar no seguinte trecho, retirado de um memorial:

Aos poucos sinto que vou aprendendo a pôr no papel as minhas vivências como professora e opiniões pessoais, o tem sido ótimo [...] é como desabafar o que teríamos vergonha de falar publicamente, porque isso também inclui sentimentos dificeis de dizer, assim, de primeira. Perceber que as coisas que acontecem no exercício de nossa profissão podem e devem ser relembradas e lidas para colegas, a fim de servirem como reflexão, é importante [...] Considero que estou vivendo uma experiência que poderá servir para uma vida inteira. (Professora/aluna X13)

As escritas memorialísticas e, posteriormente, as socializações, ao serem acionadas nos citados campos, demonstraram levar a engendramentos de outros movimentos de professoralização, a uma compreensão dos potenciais de atualização de como vinha se constituindo a professoralidade de cada professor (PEREIRA, 2010a; 2013). Nos ateliês, tornou-se possivel o acionamento de diferentes dimensões do exercício da memória - em especial como potencialidade de produzir-se a diferença, em suas sinuosidades, dinâmicas de desterritorialização, de desmanchamento de tramas constitutivas de diferentes estados de ser (DELEUZE, 1988), que foram transparecendo e, no processo, engendraram ocorrências de de- 
nominadas experiências microestéticas - que, como arranjos de forças vivas, deixaram entrever a constituição de renovadas composições de ser-sendo. Estes movimentos, processuais, ocorreram como potências de devires, a impulsionar estados de mutação e produção de outras experiências, de criação de circunstâncias que demonstraram probabilidades de redesenhos pessoais e profissionais. No segmento a seguir, pinçado no desenrolar da socialização de memoriais e conversações, isto fica explicitado:

[...] As escritas e as trocas com os colegas, nos ateliês, têm me feito refletir, me rever e me redescobrir como pessoa que inicialmente não queria trabalhar na área da educação [...] hoje não me vejo mais fazendo outro trabalho, é cansativo, muito puxado, mas não me vejo fazendo outra coisa [...] e até me sinto mais feliz depois dessas experiências com os colegas, [...] vejo que ninguém aprende no vazio, sozinho e sim comparando o que já domina, ampliando com a novidade e, quem sabe, trabalhando diferente [...] daí, embora seja difícil, desejo aprofundar conhecimentos para prosseguir com maior segurança. (Professor/aluno X2)

Claro está que, ao incentivar o acionamento de informações dessa natureza, tivemos intenções formativas de ir além da cronologia dos acontecimentos, da ideia de consolidação do presente (o que foi a justificar e sustentar $o$ que é), numa concepção identitária (PEREIRA, 2013), que se dá na historicidade. A linguagem atuou como dispositivo constituidor de tramas em sentidos de ultrapassar o meramente linguístico - não apenas na direção de oportunizar partilhas do sensivel, mas convocar à decolagem para outros lugares, resgatar experiências de processos formativos, acontecimentos, novas proposições, empregadas como ações didáticas - expressões literárias e musicais, fotografia, audiovisual, artes plásticas - como prováveis ativadoras de efeitos nas percepções, nos sentimentos, e como presu- miveis provocadoras de lembranças de traços existenciais superpostos. Nessa direção, foram utilizadas situações evocativas de memória (CHAVES, 2006), na condição de aberturas a descontinuidades que nos atravessam (FOUCAULT, 1993). No fragmento selecionado, a seguir, podem-se observar traços e aspectos que dizem da alternância, do desfazimento de si e da composição de um processo interminável de reinvenção, de criação de novos movimentos de professoralização:

[...] no início da docência, eu transferia para os alunos as agruras vividas quando fui aluna e vejo que era uma professora temida por eles. Hoje já não pratico o terrorismo e venho aprendendo mais: a não ser autoritária, principalmente. Passei a ouvi-los como pessoas e não mais retiro o recreio que é um direito deles, não mando mais copiar palavras e frases como castigos. Essas são coisas que já foram banidas de minha prática. Trato os alunos com mais humanização [...]. (Professora/aluna X10)

No processo, veem-se novos campos de complexidade que se abrem, a partir da utilização das narrativas de si, planejadas como recursos evocativos de memórias e como um rico exercício de transgressão; a multiplicidade de linguagens acionadas demonstrou um poder de avivar rememorações, de abrir subjetividades, revigorar pontos de eclosão atualizadores de marcas, sintonias, afetos, produções de sentido e forças de (re)invenção de realidades profissionais e psicossociais; com isso, pareceram suscitar, nos sujeitos-em-prática, uma atividade produtiva, uma recriação de informações e de outras escutas do tempo em andamento, de genealogia deflagradora de forças visíveis e invisiveis, de experiências intensivas com afetamentos. Estes movimentos foram inseridos no âmago deste processo investigativo/formativo, na perspectiva de ativarem entradas na potência do tempo em andamento, numa pretensa desinstalação de ordens relacionadas a uma circunscrita estabilidade, de percursos 
formativos "[...] que acompanham e se fazem ao mesmo tempo em que o desmanchamento de certos mundos [... ] e a formação de outros" (ROLNIK, 1989, p. 15). Tais entradas, sobre as experiências e as chamadas memórias de formação, a partir da proposição de escritas e relatos de si, processaram-se na compreensão de que os fenômenos e as experiências do percurso escolar se expressam nos quefazeres docentes, desde que, na condição de alunos, as pessoas chegam à instituição escolar.

Assim, trazidos para os contextos dos ateliês, os memoriais produzidos funcionaram como dispositivos de pesquisa de si-para-simesmos (RICOUER, 1995; 2007). Plenos de virtualidades, tais instrumentos deram indícios de constituírem-se num sistema portador de alto nível de energia, potencialmente mobilizadora; os resgates coletivos das narrativas de si, ao trazerem à pauta pontos singulares, reativados, foram explicitando realidades e experiências vividas - em especial na instituição escolar - a articularem sujeitos e coletivos sociais. Desenvolveram-se numa espécie de partilha do sensivel (RANCIÈRE, 2005), na qual se acentuou a recuperação/reatualização de forças vitais - nas quais o presente, ao convocar o passado e o futuro, como dimensões informativas e portadoras de sentido, se abriu para processos metaestáveis; nas tramas narrativas, conforme pode se ver a seguir, os sujeitos davam mostras de defasarem-se em relação a si próprios e produzirem marcas novas.

Estudei numa escola onde a professora se sentia e se portava como chefe de escravos e, quando passei a ensinar, vi que eu, também, só sabia ser professor assim. Com o tempo, fui me sentindo mal porque minha natureza não era aquela. [...] Nesse Curso e com as oportunidades de repensar minha prática, através das narrativas, venho mudando, vendo outras possibilidades [...] percebo que posso desafiar os alunos a aprenderem sem precisar maltratar, nem a mim, nem a eles [...]. (Professor/aluno X6)
A trajetória docente, a manifestar-se em constante reorganização - como fluxos existenciais - demonstra a potencialização do sujeito em relação a si próprio (MIDLEJ, 2014). No discurso do professor, o ambiente vivo das experiências didáticas remete a uma força provocativa de rupturas e rearranjos de possibilidades "[...] de acolhimento dos múltiplos que vivem em nós [...]" (MIDLEJ, 2014, p. 320). Parece confirmar que a pressão dos acontecimentos de desfiguração e reconfiguração da professoralidade instaura rugosidades e sinuosidades nos movimentos de professoralização (MIDLE); PEREIRA, 2014).

Em tais dimensões, além das ações realizadas nos citados ateliês e das escritas de si, concretizadas nos memoriais, criamos um plano extensional de recolha de informações, através de conexões individuais e da ativação de conversações com os professores/alunos; realizadas em diferentes circunstâncias e contextos, elas aconteceram com a finalidade de ampliar o campo dos possíveis desta ação. A tradução desse processo trouxe uma compreensão ampliada de um complexo de tramas envolvido em linguagens que, ao se afetarem umas às outras, tornaram obsoletas figuras existentes e forneceram indícios de ajudar a criar presumíveis potências e ressonâncias de si, nas quais, passado, presente e futuro tendem a se conectar e a se redimensionar em sempre novas constelações - não mais como um encadeamento cronológico, mas como um processo de (re)criação de significados e parte do processo de fazer a história.

A articulação das memórias, com a descrição das forças históricas que as constituíram e, seus enfrentamentos, intensificaram, nos partícipes, uma atividade produtiva, uma recriação de informações e de outras escutas do tempo em andamento, numa espécie de genealogia deflagradora de forças visiveis e invisiveis, de experiências intensivas com afe- 
tamentos (ROLNIK, 1993). As narrativas, amplificadas nos ateliês, reacenderam uma pluralidade de vozes, evidenciaram promover preciosos movimentos de ativação da oralidade do grupo, além de agenciarem uma valorização da escuta sensivel - acompanhada de mediações e reapropriações singulares de experiências:

Já domei cavalo bravo, jegue, já derrubei boi no campo, não tinha medo de nada. Como não havia escola na roça, a partir dos sete anos meu pai me ensinava com um $A B C$ e depois uma cartilha e me incentivava a fazer contas. Minha mãe aí aproveitava e me pedia pra escrever cartas para meus irmãos que moravam em São Paulo. Com isso eu me desenvolvia mais na escrita e quando fui para a escola, no povoado, dava aulas para os colegas: tomava lição, fazia ditado, ensinava a copiar os números e a fazer pequenas contas do jeitinho que meu pai fazia [...] eu achava incrivel como aprendia, mais ainda, ao ensinar [...] aquela experiência foi o alicerce da profissão que exerço, com orgulho, hoje. Com os estudos e estes ateliês venho aprendendo a ter outro olhar para a docência e venho querendo uma prática diferente [...] agora sinto mais segurança, autonomia, me apoio nas teorias para agir [...] antes eu pensava que todos eram iguais no modo de aprender e quem não aprendia era por preguiça [...] hoje sei que cada pessoa tem sua maneira de construir conhecimentos e eu sou quem precisa arrumar meios de trazer os assuntos através das experiências dos alunos. (Professora/aluna X15)

Como demonstrado, a ativação de repertórios de lembranças (memória retentiva), através de intensas ações de mediação, demonstrou as probabilidades de intensificar a memória projetiva e minar forças de resistência a mudanças, parecendo ampliar a capacidade de afetação ao inédito de ser-sendo professor (PEREIRA, 2010a; 2010b). As explicitações de realidades e experimentações de histórias de vida deram mostras, no decorrer do processo, de provocar reatualizações de marcas subjacentes a estados de ser atuais (ROLNIK, 1993), em que o universo social e histórico da insti- tuição escolar foi se revelando como espaço privilegiado de produção de si e da professoralidade (PEREIRA, 1996). Com isso, trouxeram fortes evidências de dissolução de concepções fixistas dos professores/alunos, dando indícios de que as explicitações de si, à medida que se processavam, criavam presumíveis potências e ressonâncias, marcas novas de vir a ser outro(s) de si.

Como recurso epistemológico e metodológico, os ateliês demonstraram a sua importância estratégica na recolha das informações e das compreensões relacionadas à subjetividade docente, ao trazerem, nas mesmas histórias de vida, os movimentos de professoralização (PEREIRA, 2010a) e, nestes, a professoralidade do professor (PEREIRA, 1996; 2001; 2010a; 2010b; 2013), juntamente com as aprendizagens construídas no espaço de formação acadêmica. Ao mesmo tempo, as conversações individuais, envolvendo implicações e distanciamentos de cada um em relação a sua escrita narrativa, configuraram-se como aprendizagens e (re)criação de significados a provocarem novas traduções, compreensões ampliadas de si e da profissão docente. Assim, as atividades desenvolvidas, não apenas nos ateliês, pareceram subverter restritos modos de olhar a realidade, indicando que, ao trazerem à pauta experiências que se afetavam umas às outras, tornavam obsoletas figuras existentes e reativavam traços de potências de devires. As narrativas (auto)biográficas, ao sancionarem o tempo em andamento, provocaram ressonâncias do presente e, ao longo dos encontros, deram mostras de convocar o passado e o futuro, como dimensões simultâneas, a abriremse para instâncias (in)formativas; funcionaram como propiciadoras de percepções, sensações e inquietações pessoais, como proliferadoras de ser/vir-a-ser, desencadeadoras de dinâmicas de transformação, de novos movimentos de ser (MIDLEJ, 2007; 2009). 
Processualmente e, após a realização de cada ateliê, foram realizadas ações de organização e leituras preliminares dos memoriais revisitados; foram acionadas também as informações registradas em meu diário de campo, além das gravações feitas a partir de conversações individuais e coletivas: o rigor do investimento em leituras densas, cruzadas e pré-analíticas, no conjunto das narrativas, permitiu-nos apreender, nas realidades experienciadas, regularidades e irregularidades históricas, marcas particulares, subjetividades, traços singulares, o que possibilitou o agrupamento dos escritos e das falas em unidades temáticas de análise. Constantes retornos aos materiais produzidos foram, paulatinamente, ampliando as perspectivas desta ação e auxiliando na realização de novos agrupamentos, com repetidas análises interpretativas e compreensivas das informações produzidas (SOUZA, 2014). As proposições de Pineau (2004) relativas à triangulação formativa de histórias de vida, em contextos de pesquisa e formação, complementaram este processo interpretativo/compreensivo, através das relações de conversações, dialogicidade e reciprocidade com os professores/alunos. Nestes procedimentos descritos contamos com as contribuições do trabalho cartográfico, em sua perspectiva de reconstrução da experiência - em suas modulações e movimentos permanentes, redesenhamentos da rede de forças que se processam na realidade - como artificio de (re)criação de tramas (in)visiveis de forças humanas interagentes (PASSOS; KASTRUP; ESCOSSIA, 2010). Ao exercitar a escuta perspicaz dessas narrativas de si - nas quais cada um dos partícipes conjugava seus modos de pensar e agir - constatamos, amiúde, a presença de dispositivos representacionais e referências binárias relacionadas à profissão docente bom professor/mau professor, que ainda se impõem como crenças e contribuem para enfatizar uma identidade profissional cristalizada.
Por fim, nesta denominada investigaçãoformação, ficaram reveladas múltiplas compreensões:

a) Ainda há traços fortes de hierarquização, fragmentação e homogeneização, em plena vigência na instituição escolar, aliados à ilusão da estabilidade. Tais elementos trouxeram à pauta um modelo hegemônico de sociedade a dar sustentação à Escola;

b) As narrativas (auto)biográficas, ao ocorrerem como processos metaformativos, a partir de perspectivas relacionais, linguísticas e reflexivas, apresentaram a história acontecendo como possibilidade de transformação; demonstraram a provocação de desarranjos e rearranjos, nas itinerâncias pessoais e profissionais, ratificando que a consciência de si é sempre verbal (BAHKTIN, 1992). Estas ações ocasionaram, nos partícipes, a ampliação das percepções de si e o aguçamento de seus entendimentos acerca das situações nas quais eles estão inseridos, demonstrando que as marcas, explicitadas, possuem um valor contextual, ao proporcionarem momentos privilegiados de confrontações com rígidas estruturas e crenças advindas da tradição racionalista. Evidenciaram, assim, que uma politica de formação docente não pode mais ser reduzida a um domínio apenas cognitivo, mas se abrir crescentemente às diferenciações e peculiaridades dos sujeitos concretos, à estetização epistemológica do mundo contemporâneo (WELSCH, 1995; 2007).

c) Ficou manifesta que uma abertura para vivências que não se pautem apenas pela dimensão cognitiva tende a provocar um fluxo formativo experiencial, poroso, a envolver a sensibilidade, o diálogo e a imaginação - parecendo liberar acontecimentos de desfiguração e reconfiguração da professoralidade; nesse sentido, a ação, como um todo, pareceu instaurar rugosidades e sinuosidades na professoralidade dos partícipes, 
dando mostras de que uma ação envolvendo a dimensão estética poderá gerar rupturas e perspectivas para incipientes movimentos docentes, eivados de reconfigurações em perspectivas mais críticas e ampliadoras de padrões idealizados.

Houve, enfim, uma clareza de que as perspectivas contidas na linguagem, como um dos modos de aproximação do universo do outro, se constituíram como valiosos aportes fenomenológicos e hermenêuticos, reafirmando a importância formativa dos atos de narrar-se

\section{Referências}

ARANHA, M. L. A. História da educação: geral e Brasil. São Paulo: Moderna, 2006.

BAHKTIN, M. Estética da criação verbal. Tradução de Maria Ermantina Galvão G. Pereira. São Paulo: Martins Fontes, 1992.

BERGER, P. L.; LUCKMANN, T. A construção social da realidade: tratado da sociologia do conhecimento. 23. ed. Tradução de Floriano de Souza Fernandes. Petrópolis, RJ: Vozes, 2003.

BRASIL. Decreto no 6.755, de 29 de janeiro de 2009. Institui a Política Nacional de Formação de Profissionais do Magistério da Educação Básica. CAPES, Ministério da Educação, 2009.

CHAVES, S. N. Memória e auto-biografia: nos subterrâneos da formação docente. In: SOUZA, E. C. (Org.). Autobiografias, histórias de vida e formação. Porto Alegre: EDPUCRS; Salvador: EDUNEB, 2006. p. 161-176.

DELEUZE, G. Diferença e repetição. Tradução de Luiz B. L. Orlandi e Roberto Machado. Rio de Janeiro: Graal, 1988.

Foucault. Tradução de Claudia Sant'Anna. Martins. 2. ed. São Paulo: Brasiliense, 1991.

DELEUZE, G; GUATTARI, F. Mil platôs: capitalismo e esquizofrenia. v. 1. Tradução de Aurélio Guerra Neto e Célia Pinto Costa. Rio de Janeiro: Ed. 34, 1995.

DELORY-MOMBERGER, C. Formação e socialização: e às práticas educacionais cotidianas. Neste reconhecimento, argumentamos em favor de uma concepção de formação como autoformação, na qual o sujeito, ao viver experiências de si, tende a produzir forças vitais criadoras de estados inéditos de ser, ao rearranjar-se, identificar-se e diferenciar-se em fontes inesgotáveis de sentidos. Tais experiências de liberação de subjetividades, na condição de professor, parecem criar uma infindável existência de potencialização do exercício de outros movimentos de professoralização.

os ateliês biográficos de projeto. Educação e Pesquisa, São Paulo, v. 32, n. 2, p. 357-371, mai./ago. 2006.

Biografia e educação. Figuras de indivíduo -projeto. Tradução de M. C. Passeggi, João Gomes Neto e Luis Passeggi, São Paulo: Paulus; Natal: EDUFRN, 2008.

DILTHEY, W. A construção do mundo histórico nas ciências humanas. Tradução de Marco Casanova. São Paulo: Editora UNESP, 2010.

DOMINICÉ, P. O processo de formação e alguns de seus componentes relacionais. In: NÓVOA, A. E FINGER, M. (Orgs.). 0 método (auto)biográfico e a formação. Natal: EDUFRN; São Paulo: Paulus, [1988] 2010. p. 83-95.

FERRAROTTI, F. Sobre a autonomia do método biográfico. In: NÓVOA, A.; FINGER, M. (Orgs.). 0 método (auto)biográfico e a formação. Natal: EDUFRN; São Paulo: Paulus, [1988] 2010. p. 34-57.

FOUCAULT, M. Microfísica do poder. Tradução de Roberto Machado. 11. ed. Rio de Janeiro: Graal, 1993.

A ética do cuidado de si como pratica da liberdade. In: FOUCAULT, M. Ética, sexualidade e política. Organização e seleção de textos de Manoel Barros da Motta. Tradução de Elisa Monteiro e Inês Autran Dourado Barbosa. Rio de Janeiro: Forense Universitária, 2004a. p. 99-116 
Uma estética da existência. In: FOUCAULT, M. Ética, sexualidade, política. Organização e seleção de textos de Manoel Barros da Motta. Tradução de Elisa Monteiro e Inês Autran Dourado Barbosa. Rio de Janeiro: Forense Universitária, 2004b. p. 264-287

L'Écriture de soi, dits et écrits. 1954-1988, Volume II (1976-1988). Paris: Gallimard, 2001. p. 12341249.

GADAMER, H-G. Verdade e método I e II. Tradução de Flávio Paulo Meirer. Petrópolis, RJ: Vozes, 1997.

HERMANN, N. Ética: a aprendizagem da arte de viver. Educação e Sociedade, Campinas, v. 29, n. 102, p. 1532, jan./abr. 2008.

. Ética \& educação. Outra sensibilidade. Belo Horizonte: Autêntica Editora, 2014.

JOSSO, C. Da formação do sujeito ao sujeito da formação. In: NÓVOA, A.; FINGER, M. (Org.). 0 método (auto)biográfico e a formação. Natal: EDUFRN; São Paulo: Paulus, 2010. p. 59-79.

JOUTARD, P. Desafios à história oral no século XXI. In: FERREIRA, M. M. FERNANDES, T. M.; ALBERTI, V. (Orgs.). História oral: desafios para o século XXI. Rio de Janeiro: FIOCRUZ/Casa de Osvaldo Cruz; CPDOC/ FGV, 2000. p. 33-34.

MEC/CNE/CES. Ministério da Educação. Parecer 05/2005 - Diretrizes Curriculares do Curso de Pedagogia. Artigo 8o § III. Disponível em: <http://portal. mec.gov.br/cne/arquivos/pdf/pcp05 05.pdf $>$. Acesso em: 08 abr. 2016.

MIDLEJ, J. A poética do cotidiano e a profissão docente. Práxis Educacional, Revista do Departamento de Filosofia e Ciências Humanas da Universidade Estadual do Sudoeste da Bahia, Vitória da Conquista, Edições UESB, n. 3, p. 279-298, 2007.

Percursos de constituição da professoralidade: tramas subjetivas. Revista de Educação PUCCampinas, Campinas, v. 27, p. 33-42, 2009.

Nos Ateliês (Auto)biográficos, a arte dos movimentos de professoralização. In: ABRAHÃO, M. H. M. B.; BRAGANÇA, I. F. S.; ARAÚJO, M. S. (Orgs.). Pesquisa (auto)biográfica, fontes e questões. Curitiba: CRV, 2014. p. 31-45.
MIDLEJ, J.; PEREIRA, M. V. Nas tramas da memória, os fios da professoralização. In: ENCONTRO NACIONAL DE DIDÁTICA E PRÁTICA DE ENSINO - ENDIPE, 17., 2014, Fotaleza. Anais... Fortaleza: EDUECE, 2014. V. único. p. 510-528.

NÓVOA, A. Prefácio à segunda edição. In:

(Org.). Vidas de professores. 2. ed. Porto: Porto Editora, 1995. p. 7-8.

NÓVOA, A.; FINGER, M. (Orgs.). 0 método (auto)biográfico e a formação. Natal: EDUFRN; São Paulo: Paulus, [1988] 2010.

PASSEGGI, M. C. Mediação biográfica: figuras antropológicas do narrador e do formador. In: PASSEGGI, M. C. E BARBOSA, T. (Orgs.). Memórias, memoriais: pesquisa e formação. Natal: EDUFRN; São Paulo: Paulus, 2008. p. 43-59.

Memoriais autobiográficos: escritas de si como arte. De (re)conhecimento. In.: CORDEIRO, V. M. R; SOUZA, E. C. (Orgs.). Memoriais, literatura e práticas culturais de leitura. Salvador: EDUFBA, 2010. p. 19-42.

PASSOS, E.; KASTRUP, V.; ESCÓSSIA, L. (Orgs.). Pistas do método da cartografia. Porto Alegre: Sulina, 2010.

PEREIRA M. V. A Estética da professoralidade: um estudo interdisciplinar sobre a subjetividade do professor. 1996. 293 f. Tese (Doutorado em Supervisão e Currículo) -Pontifícia Universidade Católica de São Paulo, São Paulo, 1996.

Nos supostos para pensar formação e autoformação: a professoralidade produzida no caminho da subjetivação. In: FRAZÃO, Célia et al. Ensinar e aprender: sujeitos, saberes e pesquisa. 2. ed. Rio de Janeiro: DP\&A, 2001. p. 23-41.

Pesquisa em educação e arte: a consolidação de um campo interminável. Revista lbero Americana de Educação, n. 52, p. 61-80, 2010a.

Sobre histórias de vida e autoformação: um enfoque ético e estético. In: ABRAHÃO, M. H. M. B. (Org.). (Auto)biografia e formação humana. Porto Alegre: EDIPUCRS, 2010b. p. 123-136.

Estética da professoralidade: um estudo 
sobre a formação do professor. Santa Maria: Editora UFSM, 2013.

PINEAU, G. Temporalidades na formação: rumo a novos sincronizadores. Tradução de Lúcia P. de Souza. São Paulo: Triom, 2004.

RANCIÈRE, J. A partilha do sensivel: estética e política. Tradução de Mônica Costa Netto. São Paulo: EXO Experimental org.; Ed. 34, 2005.

RICOEUR, P. Soi-même comme un autre. Paris: Seuil, 1990.

Tempo e narrativa. Tradução de Roberto Leal Ferreira. São Paulo: Papirus, 1995.

A memória, a história, o esquecimento. Tradução de Alain François. Campinas, SP: Unicamp, 2007.

ROLNIK, S. Cartografia sentimental: transformações contemporâneas do desejo. São Paulo: Estação Liberdade, 1989.

Pensamento, corpo e devir: uma perspectiva ético/estético/política no trabalho acadêmico. Cadernos de subjetividade, Núcleo de Estudos e Pesquisas da Subjetividade do Programa de PósGraduados em Psicologia Clínica da PUC-SP, v. 1, n. 2, p. 241-251, 1993.

SCHÜTZ, A. Fenomenologia e relações sociais. Rio de Janeiro: Zahar, 1979.
Sur les realitès multiples. In: SCHÜTZ, A. Le chercheur et le quotidien. Paris: Meridièns, 1987. p. 103-167.

SIMONDON, G. L'individu et sa gênese physico-biologique. Paris: PUF, 1989.

SOUSA, J. M. 0 professor como pessoa. Porto: Edições Asa, 2000.

SOUZA, E. C. 0 conhecimento de si: narrativas do itinerário escolar e formação de professores. 2004. 344 f. Tese (Doutorado em Educação) - Faculdade de Educação, Universidade Federal da Bahia, Salvador, 2004.

Diálogos cruzados sobre pesquisa (auto) biográfica: análise compreensiva-interpretativa e prática de sentido. Revista Educação, Santa Maria, RS, v. 39, n. 1, p. 39-50, jan./abr. 2014.

WELSCH, W. Estetização e estetização profunda ou: a respeito da atualidade do estético. Tradução de Álvaro Valls. Porto Arte, Porto Alegre, v. 6, n. 9, p. 7-22, mai. 1995.

Mudança estrutural nas ciências humanas: diagnóstico e sugestões. Educação, Porto Alegre, RS, ano XXX, n. 2 (62), p. 237-258, mai./ago. 2007.

Recebido em: 16.09.2016

Aprovado em: 20.11. 2016

Jussara Midlej é doutora em Educação, professora titular do Departamento de Ciências Humanas e Letras da Universidade Estadual do Sudoeste da Bahia (DCHL/UESB). Líder do Grupo de Estudos em Territorialidades da Infância e Formação Docente (GESTAR). e-mail: jumidlej@hotmail.com.

Rua José Moreira Sobrinho, s/n, Jequié, BA, CEP: 45.206-190.

Marcos Villela Pereira é doutor em Educação, professor titular do Programa de Pós-Graduação em Educação da PUCRS (PPGEdu/EH/PUCRS). Pesquisador do CNPq, Líder do Grupo de Pesquisa "Cultura, subjetividade e processos de formação". e-mail: marcos.villela@pucrs.br.

Av. Ipiranga, 6681, Prédio 15, sala 217, Porto Alegre, RS, CEP: 90.619-900 